\title{
Dress and age: the intersection of life and work
}

\author{
By JULIA TWIGG*
}

\begin{abstract}
In this article I outline the influences, intellectual and personal, that have led me to the subject of dress and age, a topic that I have explored with great enjoyment over the last decade. These have their roots in earlier academic and personal interests, and one of the aims of the article is to show how these different spheres of life and work intersect. I discuss this under three broad headings: intellectual and academic influences; longterm personal interests, particularly in history and the aesthetics of dress; and the impact of becoming an older woman.
\end{abstract}

Keywords: fashion, body, age, identity.

\section{Introduction}

My current work focuses on dress and age. In this article I hope to show how I became interested in such a subject and how matters of theory and personal life can intersect. I am interested in the ways in which dress is part of the cultural constitution of later years, operating at a directly bodily level, and the ways this has wider resonances for how we study and

* Julia Twigg, School of Social Policy, Sociology and Social Research, University of Kent, Canterbury, UK 
International Journal of Ageing and Later Life

understand age as a social category and experience. I locate these interests in the wider context of the emergence of what has been termed Cultural Gerontology.

\section{Intellectual Developments in the Field of Gerontology}

My interest in dress and age arose naturally out of earlier work on the body and embodiment. Initially, I looked at the body in terms of long-term care, focussing in particular on the provision of washing and bathing, and of personal care more in general, and I argued that carework needed to be conceptualised as a species of bodywork (Twigg 2000). In subsequent work, I explored the features of this category of work across a number of employment sectors (Twigg et al. 2011). This opened up for me a more general interest in the role of the body in ageing. And at this point, it struck me that one of the principal ways in which the body is experienced and known in age is through clothing and dress. After all, dress is the vestimentary envelope of the body: it is what is primarily seen, and it is central to how the body in age is presented socially. As such, it provides a route into debates around the constitution of age, in particular the complex interplay of cultural and physiological elements in this.

In the early, heady days of body studies, some analysts approached the body as if it were wholly constituted through discourse, caught in a web of signs, unknowable in any other way, virtually denying it any physiological base. Since then, its concrete reality has been recovered and re-asserted intellectually (Crossley 2001; Shilling 2003; Williams \& Bendelow 1998), partly in response to work on pain, but also age - for, as many observers through the centuries have pointed out, ageing is not optional. It was indeed always implausible to see the body simply as a product of culture. What was needed at this point was more work that could explore the complex interplay between physiological and cultural elements.

As a result, rather than being an absent present, as Öberg termed it in his seminal article of 1996, the body has become one of the central topics of social gerontology. My own work has contributed to this development, partly through work on bathing and washing (Twigg 2000), but more strongly in relation to clothing and dress (Twigg 2013, 2015). Dress is wholly cultural, but it intersects with the materiality of the body in age in ways 
that open up some of the central debates in social gerontology. Debates concerning, for example, the status of age as a social identity: the degree to which we are perceived, ordered and judged by our position in an age hierarchy, and the ways in which this does or does not give meaning and shape to our lives; and the role of material culture - in this case clothing in supporting or undercutting this, enabling us to perform or to resist age in differing ways. Dress also addresses debates on the moral regulation of age: the ways in which older bodies are policed and disciplined in distinctive ways and how this relates to the new freedoms, but also new demands, of consumption culture.

The new focus on the body was also linked to the influence of the wider Cultural Turn that occurred across the social sciences and humanities in the late twentieth century, associated in particular with post-structuralist, feminist and queer theory. Its impact came relatively late to gerontology, only being fully felt in the last decade or so. Since then, however, under the label of Cultural Gerontology it has become widely influential (Andersson 2002; Gilleard \& Higgs 2000, 2013, 2015; Katz 2005; Twigg \& Martin 2014), so much so indeed that it now represents some of the most lively writing in this area. With Wendy Martin, I have edited The Routledge Handbook of Cultural Gerontology (2015) that provides a position statement of this area.

The field of dress allows us to explore some of the theoretical themes emerging from these developments in relation, for example, to identity, performativity, moral regulation, governmentality and resistance. And it has done so, moreover, in ways that enable us, as gerontologists, to bring new insights into bear on mainstream social science, which has until recently ignored the topic of age. For example, the ways in which dress expresses and signals social and personal identity has been a theme of sociological and psychological literature for many years. But these perceptions had not been developed in relation to age, although, as I argue in the next section, they are central to how age is expressed, and indeed performed, at a bodily level. Performativity in Butler's $(1990,1993)$ original conception indeed had its roots in dress, though her focus was on cross dressing and drag. In relation to age, these ideas have been taken forward and developed by Laz $(1998,2003)$ through her conception of the "accomplishment of age," which draws on parallels with West and Zimmerman's concept of gender as a form of "accomplishment." 
International Journal of Ageing and Later Life

Here age - like gender - is seen as something that is repeatedly accomplished or performed by an individual, though it is at the same time something that is collective and interactive. Dress can clearly be part of this.

Dress is also an arena of moral regulation in which older bodies are policed and disciplined in distinctive ways. Particular meanings and dangers attach to dereliction in dress in old age in, for example, the harsher judgements that apply torn, stained clothing when displayed by the old, compared with the easy tolerance of ripped jeans and scruffy dress in the young; and the ways such sartorial lapses in the old signal a more general moral collapse, the threat of descent into pitiable, derelict old age, with the result that it becomes important to maintain a certain standard in age if one is not to fall outside mainstream society. This is a long-established theme in relation to old age culturally, but it has acquired a new emphasis with the arrival of new modes of governmentality in age, new disciplinary requirements linked to the wider bodily perfectionism that has increasingly marked the consumption-mediated world (Bordo 1993). Increasingly, these have been extended to older women also, so that they have become integrated into the mainstream through a common culture of consumption. With these new opportunities, these new expressive freedoms, however, have come new disciplinary requirements, so that older women are drawn into the same modes of self-government that have been internalised to younger women. Dress also provides an arena for the exploration of themes of resistance. How far, and in what ways, can, and do, older people use clothes as forms of resistance to the dominant meanings of age? In my study of older women and dress I certainly identified elements of this, though I also found strong themes of conformity, with expressions of the need to be "careful" with regard to dress in an age critical world (Twigg 2013).

The focus on dress also reflected a third strand in my earlier work. This relates to a long-term interest in the sociology of the everyday, the mundane, the quotidian. This was reflected in my earlier work on washing and bathing, and on food and eating (my doctoral work was on vegetarianism) (Twigg 1983, 2000, 2006). All these represent everyday activities that structure the day, that express individuality and identity, and that offer elements of ontological security - or unease - at a habitual, embodied level. Dress is part of this. As Entwistle (2000) argues, dress needs to be seen 
as "situated body practice"; not solely the preserve of the fashionable, but part of what we all do, on an everyday basis. This applies as much to older people as to the young, who are typically the focus of fashion talk. Work by Sophie Woodward (2007), Weber and Mitchell (2004) and Guy et al. (2001) has taken forward our understandings of how dress fits into everyday life, and in my work I have applied their insights to the day-to-day practices of older people also (Buse \& Twigg 2014a; Twigg 2013).

\section{Historical and Aesthetic Influences}

The second set of influences has come from a long-term interest in the history of dress. My first degree was in history and in many ways it remains my first love, certainly at the level of reading for pleasure. My interests have always been most strongly in social and cultural history, areas that burgeoned under the impact of the social sciences and the wider social and cultural shifts of the 1970s. And it was these impulses that in the same period took me in a reverse direction into sociology, which I studied for my master's and doctoral work at the London School of Economics.

Changes within dress history parallel these intellectual shifts. Dress history has its origins in the museum tradition of object-based scholarship. Empirical and practical in character, it focused on the details of cut, fabric and manufacture (Taylor 2002, 2004). From a different direction has come work by economic historians addressing the history of textiles which across Europe and North America formed the basis for industrial development and trade, one of the drivers of the industrial revolution, supporting national and international trade, and providing a key source of mechanical innovation (Harte 1991; Lemire \& Riello 2008). Together with the garment industry, this remains an important sector today, particularly in the emergent economies of the Far East; and these more recent developments, as we shall see, are part of the story of the changing cultural expression available to older people in the West. A third strand in dress history comes from cultural studies (Barnard 2014; Craik 1994; Crane 2000; Kaiser 2012). Here, the focus has been more on dress in the constitution of particular subgroups, especially youth cultures, though extending to other - mainly transgressive - subgroups. Mainstream, particularly middle aged or older styles, have received little attention in 
International Journal of Ageing and Later Life

this literature, reflecting the wider neglect of age as a dimension of identity. My work has aimed to redress this lack of attention.

Part of my interest has been in developing these traditions of analysis in relation to age. Clothes lie on the boundary between the body and its social presentation; and as such, they reflect ideas and norms about later years and its cultural estimation. As Breward (2000) and others argue, dress is one of the means whereby social difference is made manifest and visible. We are familiar with this in terms of the master identities such as gender and class. Indeed, gender differentiation in dress is one of the most common features of dress codes cross culturally, and social differentiation of dress in terms of class has been at the heart of sociological analysis of clothing since the time of Simmel (1904) and Veblen (1899). But such analyses apply also of age. Dress practices encode and reflect meanings about age, and in doing so help constitute age - like class and gender as a social category. Such analyses thus allow us to explore the ways social categories operate, making their cultural constitution and expression through material objects more visible.

One of the clearest ways we can see this is in terms of the long established phenomenon of age ordering in dress. By this, I mean systematic patterning of cultural expectations according to an ordered and hierarchically arranged concept of age. There is a persistent normative pattern with regard to what clothes are appropriate for people as they get older - or more significant, inappropriate as they get older, for these norms are largely expressed in negative form: what should be avoided. Though, of course, subject to historical specificity, there is a persistent pattern to such avoidances (Twigg 2013). This pattern of age ordering is long established historically. And it was clear from the empirical work I undertook that it still operates in the UK in the early twenty-first century. But there is also evidence of change. Dress norms are shifting, and older women - or at least some older women - are being drawn into the sphere of fashion. There are assumptions across the media that older women increasingly want to engage with this area and that it offers them new freedoms and pleasures. Though as the many articles addressing the perils of clothing choice in middle age show, it also offers new anxieties.

Work on the clothing system, thus, feeds into what has been termed the reconstitution of ageing thesis, which argues that a series of social, cultural 
and demographic shifts have repositioned older people nearer the mainstream. Öberg and Tornstam $(1999,2001)$ and others have suggested a new version of the life course in which later years are part of an extended shared plateau of middle life that persists until the disruption of serious ill health. Such ideas are also reflected in arguments put forward by Gilleard and Higgs (2000) about the emergence of the Third Age as a new cultural space - one marked by leisure and the pursuit of enjoyment post retirement. Such ideas are often associated with the baby boomers as a distinctive cohort. In statistically based work with an economic historian, I have explored whether expenditure patterns in areas of appearance by older women do indeed support the baby boomer analysis (Twigg \& Majima 2014). In general, our conclusion was that they do not. Data from the Family Expenditure Survey in the UK for the period from the 1960s suggest that it is period rather than cohort effects that are more significant in relation to the changing spending patterns of older women. The most significant development has been the arrival of cheap fast fashion from the 2000s, and this has been experienced across the age range. This does, however, support an argument for greater cultural integration.

As we have noted, textile and museum-based scholarship rests on a recognition of the materiality of dress. One of the gains of working in this area has been the opportunity to bring such a material analysis into age studies. This has applied in particular to the work I undertook with Christina Buse (Buse \& Twigg 2014a, 2014b, 2015a, 2015b; Twigg 2010; Twigg \& Buse 2013) on dementia and dress, where we focussed on the ways in which dress could operate at a directly material level in supporting embodied personhood. Clothes are the "environment closest in": they directly surround the individuals, are immediate to hand and touch. Their material properties and capacity to transmit memories at a directly physical level can be of special significance in circumstances of dementia. Certain objects can take on additional meanings, as we explored in our analysis the role of handbags in the lives of women with dementia living in care homes (Buse \& Twigg 2014a).

Lastly, a focus on dress has brought an aesthetic dimension to my work that was previously absent, but that reflects my enduring interest in the visual arts, painting, sculpture and especially architecture. These are central to my life and occupy much of my spare time. Turning to dress in 
International Journal of Ageing and Later Life

the final stages of my career has, thus, brought an element of visual pleasure to my work, enabling me to link up these different areas of my life, creating a space in which I can, perhaps, develop work beyond the immediate demands of an academic career. It has certainly placed me in an aesthetically more joyful area than my previous work on frailty often did. And as I get older, this is something I am grateful for.

\section{Becoming an Older Woman}

The last of my three influences is directly personal and relates to the experience of becoming an older woman. I too have faced the "changing room moment" when I have looked in the glass and realised that a style that once suited no longer does. I too have puzzled over what to wear as I get older. And this has fed into my work, helping to shape my current interest in dress and age. When I started studying older people in the 1980s, I was in my 40s. I hope that, like others in social gerontology, I was concerned with the difficulties and prejudices older people faced, and concerned to advocate their interests. But I did so - inevitably - at a distance from actual experience. Now that is increasingly no longer the case, and this has affected what I want to explore and write about in relation to age.

As a result, my work has shifted more directly to the experiences of older people, and to a focus on their - or rather increasingly for me, our ordinary lives. Social gerontology has tended to foreground problematic old age, seeing it through the lens of social welfare and public policy, in which objectifying discourses often predominate, and it has tended to neglect the subjectivity of older people, missing much of the way in which they live, evaluate and experience their lives. Under the impact of the new Cultural Gerontology, however, these concerns have moved centre stage, assisted in particular by the work in the arts and humanities which has, through the exploration of literature, theatre, art and music, placed subjectivity at the hearts of its analysis, and in doing so refreshed and immeasurably widened the context in which age is discussed.

It is also significant that I write as a woman. Though gender is now properly recognised as relevant to all scholars - women and men - the realisation of its significance arose out of the feminism of the second wave: and 
that is the generation of feminism to which I belong. That movement was central in opening up the academic agenda to subjects such as emotion, subjectivity, embodiment, sexuality and care. But in these early stages, feminism neglected age, reflecting the ageist prejudices found elsewhere in academic and cultural life. Slowly, however, feminist scholars of the second wave, as they have themselves aged, have expanded its boundaries, writing age into gender (Gullette 1997, 1999; Holstein 2006; Oakley 2007; Segal 2013). Many of the subjects that I have written about are inflected with gender: the body, care, appearance and dress. And many of them raise issues for gender politics. I am thinking in particular here of the double standards that apply to appearance and age, the processes that sideline women as they age, the differential judgements and valuations that are applied (Arber \& Ginn 1991; Calasanti 2008; Calasanti \& Slevin 2001; Gullette 2011; Holstein 2015; Hurd Clarke 2011; Hurd Clarke \& Bennett 2015; Sontag 1972; Woodward 1991, 1999, 2006). Work by feminists on gender has made these visible. Paradoxically, in doing so, it has exposed how they can also operate in relation to men, albeit mediated by different expectations and meanings. Dress is an example of this, revealing the ways in which cultural assumptions around dress and age are distinctly gendered, and yet can share common features. And in pursuit of these common features and differences, I am about to embark on a third and final stage of the clothing project in the form of a study of men and dress.

\section{Conclusion}

Academic life - for those who enjoy it - is a wonderful career. It offers an opportunity to combine personal interests, intellectual curiosity and ideally - the chance to contribute to the wider society through the growth of knowledge and the application of it to common problems. I am immensely grateful to the university system in the UK for giving me this. I nearly missed out. I started life as a historian, moved across into sociology, particularly the sociology of religion in pursuit of more theoretical engagement and a wider intellectual agenda, but the cold winds of the 1980s and the crisis in the UK university system of that time blew me off course. I managed, however, to steer myself back via an period in the health service that turned me into a social policy analyst, 
International Journal of Ageing and Later Life

and in doing so I discovered the field of social gerontology. Since then I have worked, with the greatest enjoyment, in that field. What dress has given to me, in this context, is a chance to draw together many of the earlier stands of my work, and to unite them with personal interests and experiences in a way that has greatly enriched my life.

\section{Corresponding Author}

Julia Twigg, School of Social Policy, Sociology and Social Research, University of Kent, Canterbury CT2 7NF, UK. Email: j.m.twigg@kent.ac.uk

\section{References}

Andersson, L. (ed.) (2002). Cultural Gerontology. Westport, CT: Auburn House.

Arber, S. \& Ginn, J. (1991). Gender and Later Life: A Sociological Analysis of Resources and Constraints. London: Sage.

Barnard, M. (2014). Fashion Theory: An Introduction. London: Routledge.

Bordo, S. (1993). Unbearable Weight: Feminism, Western Culture and the Body. Berkley, CA: University of California Press.

Breward, C. (2000). Cultures, identities, histories: Fashioning a cultural approach to dress. In N. White \& I. Griffiths (eds.), The Fashion Business: Theory, Practice, Image (pp. 23-36). Oxford: Berg.

Buse, C. \& Twigg, C. (2014a). Women with dementia and their handbags: Negotiating identity, privacy and 'home' through material culture. Journal of Aging Studies 30: 14-22.

Buse, C. \& Twigg, J. (2014b). Looking 'out of place': Analysing the spatial and symbolic meanings of dementia care setting through dress. International Journal of Ageing and Later Life 9(1): 69-95.

Buse, C. \& Twigg, J. (2015a). Materialising memories: Exploring the stories of people with dementia through dress. Ageing \& Society. doi: http:// dx.doi.org/10.1017/S0144686X15000185

Buse, C. \& Twigg, J. (2015b). Clothing, embodied identity and dementia: Maintaining the self through dress. Age, Culture, Humanities (2).

Butler, J. P. (1990). Gender Trouble: Feminism and the Subversion of Identity. London: Routledge. 
Butler, J. P. (1993). Bodies that Matter: On the Discursive Limits of 'Sex'. London: Routledge.

Calasanti, T. (2008). Theorizing feminist gerontology, sexuality, and beyond: An intersectional approach. In V. Bengtson, D. Gans, N. Putney \& M. Silverstein (eds.), Handbook of Theories of Aging (pp. 471-485). New York: Springer.

Calasanti, T. M. \& Slevin, K. F. (2001). Gender, Social Inequalities, and Aging. New York: Alta Mira Press.

Craik, J. (1994). The Face of Fashion: Cultural Studies in Fashion. London: Routledge.

Crane, D. (2000). Fashion and Its Social Agendas: Class, Gender and Identity in Clothing. Chicago, IL: University of Chicago Press.

Crossley, N. (2001). The Social Body: Habit, Identity and Desire. London: Sage.

Entwistle, J. (2000). The Fashioned Body: Fashion, Dress and Modern Social Theory. Cambridge: Polity Press.

Gilleard, C. \& Higgs, P. (2000). Cultures of Ageing: Self, Citizen and the Body. London: Prentice Hall.

Gilleard, C. \& Higgs, P. (2013). Ageing, Corporeality and Embodiment. London: Anthem Press.

Gilleard, C. \& Higgs, P. (2015). The cultural turn in gerontology. In J. Twigg \& W. Martin (eds.), The Routledge Handbook of Cultural Gerontology (pp. 29-36). London: Routledge.

Gullette, M. M. (1997). Declining to Decline: Cultural Combat and the Politics of Midlife. Charlottesville, VA: University Press of Virginia.

Gullette, M. M. (1999). The other end of the fashion cycle: Practising loss, learning decline. In K. Woodward (ed.), Figuring Age: Women, Bodies, Generations (pp. 34-55). Bloomingdale, IL: Indiana University Press.

Gullette, M. M. (2011). Agewise: Fighting the New Ageism in America. Chicago, IL: University of Chicago Press.

Guy, A., Green, E. \& Banim, M. (2001). Introduction. In A. Guy, E. Green \& M. Banim (eds.), Through the Wardrobe: Women's Relationships with Their Clothes (pp. 1-17). Oxford: Berg.

Harte, N. B. (ed.) (1991). Fabrics and fashions: Studies in the economic and social history of dress. Special Issue of Textile History 22(2): 150-358. 
International Journal of Ageing and Later Life

Holstein, M. (2006). On being an aging woman. In T. M. Calasanti \& K. F. Slevin (eds.), Age Matters: Realigning Feminist Thinking (pp. 313-334). New York: Routledge.

Holstein, M. (2015). Women in Late Life: Critical Perspectives on Gender and Age. Lanham: Rowman \& Littlefield.

Hurd Clarke, L. (2011). Facing Age: Women Growing Older in Anti-aging Culture. Lanham: Rowman \& Littefield.

Hurd Clarke, L. \& Bennett, E. V. (2015). Gender, ageing and appearance. In J. Twigg \& W. Martin (eds.), The Routledge Handbook of Cultural Gerontology (pp. 133-140). London: Routledge.

Kaiser, S. B. (2012). Fashion and Cultural Studies. London: Berg.

Katz, S. (2005). Cultural Ageing: Life Course, Lifestyle and Senior Worlds. Peterborough, ON: Broadwood.

Laz, C. (1998). Act your age. Sociological Forum 13(1): 85-113.

Laz, C. (2003). Age embodied. Journal of Aging Studies 1(4): 503-519.

Lemire, B. \& Riello, G. (2008). East and west: Textile and fashion in early modern Europe. Journal of Social History 41(4): 887-916.

Oakley, A. (2007). Fracture: Adventures of a Broken Body. Bristol: Policy Press.

Öberg, P. (1996). The absent body - A social gerontological paradox. Ageing \& Society 16(6): 701-719.

Öberg, P. \& Tornstam, L. (1999). Body images among men and women of different ages. Ageing \& Society 19(5): 629-644.

Öberg, P. \& Tornstam, L. (2001). Youthfulness and fitness - Identity ideals for all ages? Journal of Ageing and Identity 6(1): 15-29.

Segal, L. (2013). Out of Time: The Pleasures and Perils of Ageing. London: Verso.

Simmel, G. (1971[1904]). On Individuality and Social Forms: Selected Writings. Chicago, IL: University of Chicago Press.

Shilling, C. (2003). The Body and Social Theory ( $2^{\text {nd }}$ ed.). London: Sage.

Sontag, S. (1972). The double standard in aging. The Saturday Review 23: 29-38.

Taylor, L. (2002). The Study of Dress History. Manchester: Manchester University Press.

Taylor, L. (2004). Establishing Dress History. Manchester: Manchester University Press.

Twigg, J. (1983). The meaning of meat. In A. Murcott (ed.), The Sociology of Food and Eating (pp. 18-30). Aldershot: Gower. 
Twigg, J. (2000). Bathing, the Body and Community Care. London: Routledge. Twigg, J. (2006). The Body in Health and Social Care. Basingstoke: Palgrave. Twigg, J. (2010). Clothing and dementia and dress: A neglected dimension. Journal of Aging Studies 24(4): 223-230.

Twigg, J. (2013). Fashion and Age: Dress, the Body and Later Life. London: Bloomsbury.

Twigg, J. (2015). Dress and age. In J. Twigg \& W. Martin (eds.), The Routledge Handbook of Cultural Gerontology (pp. 149-156). London: Routledge.

Twigg, J. \& Buse, C. (2013). Dress, dementia and the embodiment of identity. Dementia 12(3): 326-336.

Twigg, J. \& Majima, S. (2014). Consumption and the constitution of age: Expenditure patterns of clothing, hair and cosmetics among post war 'baby boomers'. Journal of Aging Studies 30: 23-32.

Twigg, J. \& Martin, W. (2014). The challenge of cultural gerontology. The Gerontologist 55(3): 353-359.

Twigg, J. \& Martin, W. (eds.) (2015). The Routledge Handbook of Cultural Gerontology. London: Routledge.

Twigg, J., Wolkowitz, C., Cohen, R. \& Nettleton, S. (2011). Conceptualising body work in health and social care. Sociology of Health and Illness 33(2): 171-188.

Veblen, T. (1953[1899]). The Theory of the Leisure Class: An Economic Study of Institutions. New York: Mentor.

Weber, S. \& Mitchell, C. (eds.) (2004). Not Just Any Dress: Narratives of Memory, Body and Identity. New York: Lang.

Williams, S. J. \& Bendelow, G. (1998). The Lived Body: Sociological Themes, Embodied Issues. London: Routledge.

Woodward, K. (1991). Aging and Its Discontents, Freud and Other Fiction. Bloomington, IN: Indiana University Press.

Woodward, K. (ed.) (1999). Figuring Age: Women, Bodies, Generations. Bloomington, IN: Indiana University Press.

Woodward, K. M. (2006). Performing age, performing gender. NWSA Journal 18(1): 162-189.

Woodward, S. (2007). Why Women Wear What They Wear. Oxford: Berg. 